\title{
Usulan Perbaikan Kualitas Produk Labu Ukur Menggunakan Fault Tree Analysis (FTA) dan Failure Mode Effect Analysis (FMEA) di CV. X
}

\author{
Krida Cipta N*, Dewi Shofi Mulyati \\ Prodi Teknik Industri, Fakultas Teknik, Universitas Islam Bandung, \\ Indonesia.
}

*kridacipta@gmail.com, dewi.shofi@unisba.ac.id

\begin{abstract}
Quality control is activities to be able to improve, maintain and improve the quality of the products produced. Because it controls the quality, it is very important to improve the quality of the products produced. Can improve the quality expected by all elements of the company can be obtained as expected. CV. X is a company established in the city of Bandung in 2003, Jakarta, Bogor and Central Java. The company is engaged in the production of various laboratory equipment such as erlenmayer, test tubes, drip pipettes, measuring flasks and measuring cups. The number of pumpkin production in 2016 was 2218, in 2017 as many as 2429 and in 2018 as many as 2871 . Of the total production, the level of defect of pumpkin products measured an increase in 2016 of $3.5 \%$, in 2017 amounted to $4.3 \%$ and in 2018 of 5.3\%. The level of product defect exceeds the target or determined by the company for smoothness of $2 \%$, it is necessary to improve the quality of product defects in the flask. Fault Tree Analysis (FTA) and Failure Mode and Effect Analysis (FMEA) can be used to analyze and provide solutions to improve the quality of defective products. Based on the processing and analysis of the data obtained on the type of defective form is not appropriate is the operator who is not careful with the value of RPN 120, the cause of screen printing defects that consider cleanliness, less careful, dirty work area, the user uses the operator to reverse the setting with the RPN value 144, causing damage back / broken ie operator settings change, less careful and less tidy work station with a value of RPN 240.
\end{abstract}

Keywords: quality, volumetric flask, defect.

Abstrak. Pengendalian kualitas merupakan aktivitas-aktivitas untuk dapat menjaga, mempertahankan dan dapat meningkatkan kualitas dari produk yang dihasilkan. Oleh karena hal tersebut pengendalian kualitas memiliki peranan sangat penting dalam terciptanya produk yang berkualitas. Sehingga tujuan yang diharapkan oleh seluruh elemen perusahaan dapat tercapai. CV.X merupakan perusahaan yang didirikan di Kota Bandung pada tahun 2003, berbasis usaha kecil menengah dengan pangsa pasar meliputi wilayah Bandung, Jakarta, Bogor dan Jawa Tengah. Perusahaan ini bergerak dalam produksi berbagai macam alat-alat laboratorium seperti erlenmayer, tabung reaksi, pipet tetes, labu ukur dan gelas ukur. Jumlah produksi labu ukur pada tahun 2016 adalah 2218, pada tahun 2017 sebanyak 2429 dan pada tahun 2018 sebanyak 2871 . Dari jumlah produksi tersebut, tingkat kecacatan produk labu ukur mengalami peningkatan yaitu pada tahun 2016 sebesar $3.5 \%$, tahun 2017 sebesar 4,3\% dan tahun 2018 sebesar 5,3\%. Tingkat kecacatan produk sudah melewati ambang batas dari yang diharapkan perusahaan sebesar $2 \%$ sehingga diperlukan upaya unuk mengatasi masalah kecacatan produk pada labu ukur. Fault Tree Analysis (FTA) dan Failure Mode and Effect Analysis (FMEA) dapat digunakan untuk menganalisis dan memberikan solusi terhadap perbaikan kualitas produk cacat. Hasil dari data yang telah diolah dan dianalisa, faktor penyebab kecacatan bentuk tidak sesuai yaitu operator kurang hati-hati dengan nilai RPN 120, penyebab cacat sablon yaitu perhatian terhadap kebersihan kurang, kurang hati-hati, stasiun kerja kotor, intensitas penggunaan alat tinggi, kurangnya pengawasan dan operator mengabaikan setting dengan nilai RPN 144, penyebab cacat retak/pecah yaitu operator mengabaikan aturan setting, kurang hati-hati dan stasiun kerja kurang rapi dengan nilai RPN 240.

Kata Kunci: kualitas, labu ukur, kecacatan. 


\section{A. Pendahuluan}

Perkembangan industri farmasi setiap tahunnya mengalami peningkatan yang signifikan, menurut data dari Kalbe Company perkembangan pasar farmasi di Indonesia tumbuh rata-rata $20,6 \% /$ tahun. Tentu saja hal ini memberikan peluang terhadap perusahaan yang memproduksi alat-alat kimia untuk meningkatkan peluang pemasarannya. Untuk itu perusahaan yang memproduksi alat kimia dituntut untuk selalu berinovasi terhadap perkembangan produk dan kualitas produk demi memenuhi permintaan industri farmasi. Dengan memproduksi produk dengan kualitas yang tinggi maka daya saing perusahaan akan meningkat seiring banyaknya konsumen yang menginginkan produk dengan kualitas tinggi. CV. X merupakan perusahaan yang didirikan di Kota Bandung pada tahun 2003, berbasis usaha kecil menengah dengan pangsa pasar meliputi wilayah Bandung, Jakarta, Bogor dan Jawa Tengah. Perusahaan ini bergerak dalam produksi berbagai macam alat-alat laboratorium seperti erlenmayer, tabung reaksi, pipet tetes, labu ukur dan gelas ukur. Dari seluruh produk yang dihasilkan, CV. X perlu memperhatikan kualitas produknya antara lain perlu memperhatikan bentuk yang sesuai spesifikasi pelanggannya, ukuran yang sesuai dan ketahanan produk. Produk labu ukur merupakan produk yang sering mengalami kecacatan, karena produk tersebut memiliki tingkat kesulitan yang tinggi sehingga kualitas yang ditetapkan terkadang sulit tercapai. Berikut adalah data produk labu ukur yang cacat dari tahun 2016-2018.

Tabel 1. Data Kecacatan Produk

\begin{tabular}{|c|c|c|c|c|c|c|}
\hline \multirow[b]{2}{*}{ Tahun } & \multirow[b]{2}{*}{$\begin{array}{l}\text { Jumlah } \\
\text { Produksi }\end{array}$} & \multicolumn{3}{|l|}{ Jenis Cacat } & \multirow[b]{2}{*}{$\begin{array}{l}\text { Jumlah } \\
\text { Cacat }\end{array}$} & \multirow[b]{2}{*}{$\begin{array}{l}\text { Presentase } \\
\text { Cacat }\end{array}$} \\
\hline & & $\begin{array}{l}\text { Bentuk Tidak } \\
\text { Sesuai } \\
\text { Spesifikasi }\end{array}$ & $\begin{array}{l}\text { Ukuran } \\
\text { Tidak } \\
\text { Sesuai }\end{array}$ & Retak/Pecah & & \\
\hline 2016 & 2218 & 26 & 14 & 38 & 78 & $3,5 \%$ \\
\hline 2017 & 2429 & 34 & 20 & 51 & 105 & $4,3 \%$ \\
\hline 2018 & 2871 & 42 & 31 & 79 & 152 & $5,3 \%$ \\
\hline
\end{tabular}

Sumber : CV. Glass Lestari tahun 2016-2018 ini yaitu:

Berdasarkan latar belakang masalah diatas maka tujuan yang diharapkan dari penelitian

1. Mengetahui jenis kecacatan produk labu ukur pada CV.X .

2. Mengetahui faktor - faktor yang menyebabkan produk labu ukur cacat.

3. Memberikan peningkatan kualitas produk pada CV.X .

\section{B. Landasan Teori}

Menurut Assauri (2008) kualitas merupakan 'faktor - faktor yang terdapat dalam suatu barang atau hasil yang menyebabkan barang atau hasil tersebut sesuai dengan tujuan untuk apa barang atau hasil itu dimaksudkan atau dibutuhkan. Tujuan pengendalian kualitas adalah sebagai berikut :

1. Agar barang hasil produksi dapat mencapai standar mutu yang telah ditetapkan

2. Mengusahakan agar biaya inspeksi dapat menjadi sekecil mungkin

3. Mengusahakan agar biaya desain produk dan proses dengan menggunakan kualitas produksi tertentu dapat menjadi sekecil mungkin

4. Mengusahakan agar biaya produksi dapat menjadi serendah mungkin. 
Menurut Yumaida (2011) FTA adalah sebuah teknik analisis dari atas ke bawah (topdown), dimana kejadian yang tidak diharapkan yang disebut top event diidentifikasi terlebih dahulu. Manfaat Fault Tree Analysis (FTA)) adalah sebagai berikut :

1. Dapat menentukan faktor penyebab yang kemungkinan besar menimbulkan kegagalan.

2. Menemukan tahapan kejadian yang kemungkinan besar sebagai penyebab kegagalan.

3. Menganalisa kemungkinan sumber-sumber resiko sebelum kegagalan timbul.

4. Menginvestigasi suatu kegagalan.

Menurut Tannady (2015) Failure Mode and Effect Analysis (FMEA) adalah suatu alat yang sering digunakan di dalam metode-metode perbaikan kualitas. Manfaat dari proses Failure Mode and Effect Analysis (FMEA) bagi perusahaan adalah :

1. Membantu menganalisa proses manufaktur baru.

2. Meningkatkan pemahaman bahwa kegagalan potensial pada proses manufaktur harus dipertimbangkan.

3. Mengidentifikasi defisiensi proses.

4. Menetapkan prioritas untuk tindakan perbaikan pada proses

5. Menyediakan dokumen yang lengkap tentang perubahan proses untuk memandu pengembangan proses manufaktur atau perakitan di masa mendatang.

\section{Hasil Penelitian dan Pembahasan}

\section{Identifikasi FTA}

\section{Diagram Pohon Kesalahan (Fault Tree)}

Jenis kegagalan atau kecacatan yang telat diidentifikasi kemudian didefinisikan dalam level yang lebih rendah sampai tidak dapat diuraikan lagi. Jenis kecacatan labu ukur yang pertama adalah bentuk yang tidak sesuai spesifikasi. Adapun pohon kesalahan pada jenis kecacatan ini dapat dilihat pada Gambar 1.

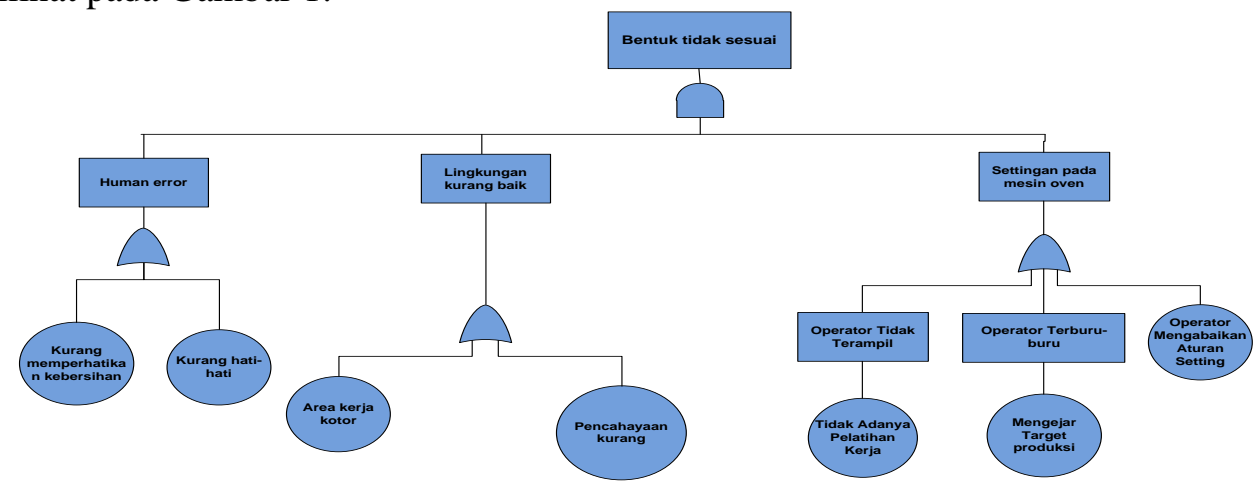

Gambar 1. Pohon Kesalahan Jenis Cacat Bentuk tidak sesuai

Berdasarkan Gambar 1. mengenai pohon kesalahan jenis kecacatan bentuk yang tidak sesuai spesifikasi, terdapat 3 faktor yang menyebabkan kecacatan, yaitu human error, lingkungan kurang baik, masalah settingan mesin. Kegagalan yang disebabkan oleh human error disebabkan karena operator kurang memperhatikan kebersihan dan kurang hati-hati. Faktor kedua yang menyebabkan kegagalan yaitu lingkungan kurang baik. Lingkungan yang kurang baik disebabkan karena area kerja yang kotor dan pencahayaan kurang. Faktor selanjutnya adalah proses setting mesin pengovenan yang tidak benar yang disebabkan oleh operator yang tidak terampil yang dikarenakan tidak adanya pelatihan kerja oleh perusahaan, operator terburu-buru karena mengejar target produksi dan operator mengabaikan aturan setting mesin. Adapun pohon kesalahan jenis kecacatan produk labu ukur yang kedua yaitu cacat pada sablon ditampilkan pada Gambar 2. 


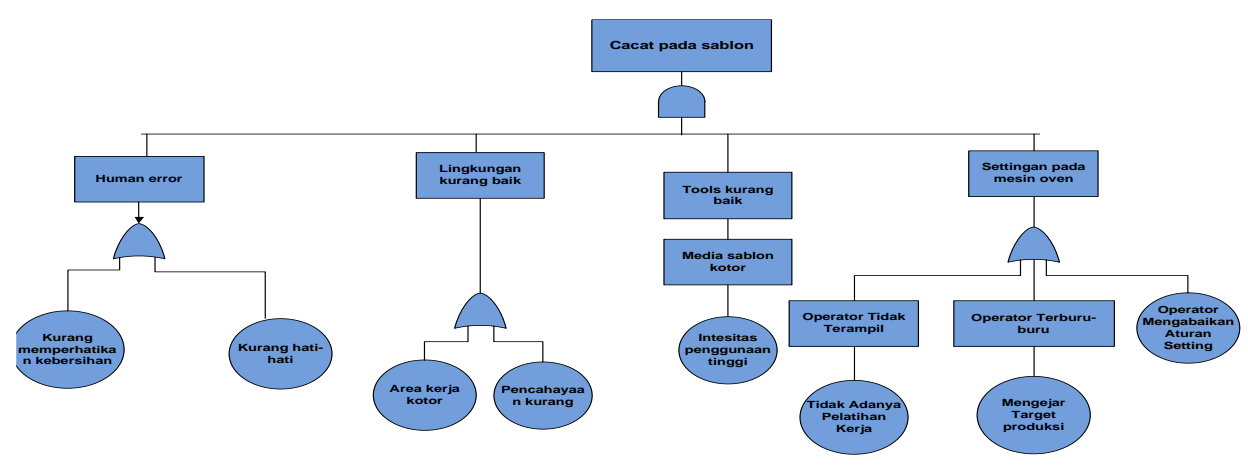

Gambar 2. Pohon Kesalahan Jenis cacat pada sablon

Berdasarkan Gambar 2. mengenai pohon kesalahan jenis cacat pada sablon terdapat 4 faktor yang menyebabkan terjadinya kecacatan. Kegagalan yang disebabkan oleh human error disebabkan karena operator kurang memperhatikan kebersihan dan kurang hati-hati. Faktor kedua yang menyebabkan kegagalan yaitu lingkungan kurang baik. Lingkungan yang kurang baik disebabkan karena area kerja yang kotor dan pencahayaan kurang. Faktor selanjutnya adalah tools yang kurang baik karena media sablon kotor yang disebabkan oleh intensitas penggunaaan tinggi. Faktor yang keempat yaitu proses setting mesin pengovenan yang tidak benar yang disebabkan oleh operator yang tidak terampil yang dikarenakan tidak adanya pelatihan kerja oleh perusahaan, operator terburu-buru karena mengejar target produksi dan operator mengabaikan aturan setting mesin. Adapun pohon kesalahan jenis kecacatan produk labu ukur yang ketiga yaitu retak/ pecah dapat dilihat pada gambar 3 .

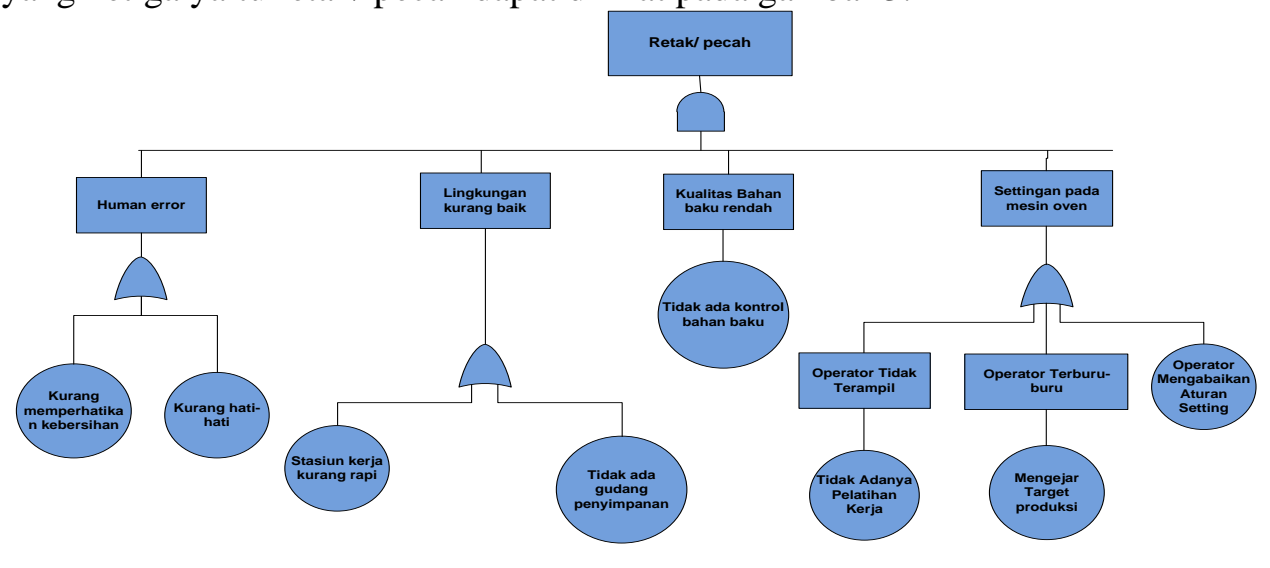

Gambar 3. Pohon Kesalahan Jenis kecacatan retak/ pecah

\section{Analisis FMEA}

Setelah mendapatkan basic event dari hasil FTA, langkah selanjutnya menggunakan proses FMEA untuk mencari solusi perbaikan kualitas produk. Prosedur dalam pembuatan FMEA meliputi 10 tahapan berikut ini (McDermott, 2009):

1. Melakukan peninjauan terhadap proses.

2. Mengidentifikasi potential failure mode (mode kegagalan potensial) pada proses. 
Potential failure mode menggambarkan cara dimana sebuah produk atau proses bisa gagal untuk melaksanakan fungsi yang diperlukan sebagai gambaran keinginan, kebutuhan dan harapan dari internal dan eksternal customer.

3. Membuat daftar potential effect (akibat potensial) dari masing-masing mode kegagalan. Dampak atau akibat yang ditimbulkan jika komponen tersebut gagal seperti disebutkan dalam potential failure mode.

4. Menentukan peringkat severity untuk masing - masing cacat yang terjadi. Severity adalah kemungkinan dampak dari kegagagalan yang terjadi.

5. Menentukan ranking occurance. Occurance adalah nilai perkiraan perbandingan produk cacat dengan jumlah keseluruhan produksi

6. Menentukan ranking detection. Ranking ini dapat melihat seberapa besar penyebab memungkinkan lolos dari kendali yang sudah ada

7. Menghitung nilai Risk Priority Number (RPN).

8. Menyusun prioritas penyebab kegagalan untuk melakukan perbaikan.

9. Meminimalisir kegagalan dengan perbaikan atau action.

10. Menghitung hasil RPN sebagai penyebab kecacatan yang diminimalir. tabel 2 .

Berikut adalah hasil dari perhitungan RPN dalam Proses FMEA yang ditunjukan pada

Tabel 2. Nilai Risk Ptiority Number (RPN)

\begin{tabular}{|c|c|c|c|c|c|}
\hline Potential Failure Mode & Potential Effect (S) Failure & $\mathrm{S}$ & $\mathrm{O}$ & $\mathrm{D}$ & $\mathrm{RPN}$ \\
\hline \multirow{7}{*}{ Bentuk yang tidak sesuai } & Perhatian akan kebersihan kurang & \multirow{7}{*}{4} & 4 & 6 & 96 \\
\hline & Kurang hati-hati & & 5 & 6 & 120 \\
\hline & Area kerja yang kotor & & 4 & 6 & 96 \\
\hline & Pencahayaan yang kurang & & 4 & 6 & 96 \\
\hline & Mengejar target produksi & & 4 & 4 & 64 \\
\hline & Tidak ada pelatihan kerja & & 4 & 5 & 80 \\
\hline & Aturan setting mesin diabaikan & & 4 & 6 & 96 \\
\hline \multirow{9}{*}{ Cacat pada sablon } & Perhatian akan kebersihan kurang & \multirow{9}{*}{6} & 4 & 6 & 144 \\
\hline & Kurang hati-hati & & 4 & 6 & 144 \\
\hline & Area kerja yang kotor & & 4 & 6 & 144 \\
\hline & Pencahayaan kurang & & 4 & 5 & 120 \\
\hline & Intensitas penggunaan alat tinggi & & 4 & 6 & 144 \\
\hline & Pengawasan kurang & & 4 & 6 & 144 \\
\hline & Mengejar target produksi & & 4 & 4 & 96 \\
\hline & Tidak ada pelatihan kerja & & 3 & 5 & 90 \\
\hline & Aturan setting mesin diabaikan & & 4 & 6 & 144 \\
\hline \multirow{8}{*}{ Retak/ pecah } & Kurang memperhatikan kebersihan & \multirow{8}{*}{8} & 4 & 6 & 192 \\
\hline & Kurang hati-hati & & 5 & 6 & 240 \\
\hline & Stasiun kerja kurang rapi & & 5 & 6 & 240 \\
\hline & Mengejar target produksi & & 5 & 4 & 160 \\
\hline & Tidak ada gudang penyimpanan & & 4 & 6 & 192 \\
\hline & Tidak ada kontrol bahan baku & & 4 & 7 & 224 \\
\hline & Tidak ada pelatihan kerja & & 4 & 5 & 160 \\
\hline & Aturan setting mesin diabaikan & & 5 & 6 & 240 \\
\hline
\end{tabular}


Berdasarkan Tabel 2. nilai RPN tertinggi penyebab kecacatan untuk bentuk tidak sesuai adalah operator kurang hati-hati. Penyebab kecacatan untuk cacat pada sablon adalah perhatian akan kebersihan kurang, tidak hati-hati, area kerja yang kotor, intensitas penggunaan alat tinggi, kurangnya pengawasan dan operator mengabaikan setting. Sedangkan untuk penyebab kecacatan retak/pecah adalah operator mengabaikan aturan setting, kurang hati-hati dan stasiun kerja kurang rapi,. Penyebab kecacatan yang telah ditentukan dari risk priority number (rpn) tertinggi menjadi fokus perhatian dalam memberikan solusi perbaikan kualitas produk labu ukur.

\section{Kesimpulan}

Berdasarkan hasil penelitian dan pengolahan data yang dilakukan, maka dapat ditarik kesimpulan sebagai berikut :

1. Dari penelitian yang telah dilakukan, jenis kecacatan pada produk labu ukur yaitu bentuk yang tidak sesuai, cacat pada sablon dan retak/pecah.

2. Bedasarkan hasil identifikasi pada produk labu ukur, faktor - faktor penyebab terjadinya kecacatan pada masing-masing jenis cacat adalah sebagai berikut :

- Bentuk yang tidak sesuai, penyebab terjadinya kecacatan yaitu perhatian akan kebersihan kurang, operator kurang hati-hati, stasiun kerja kotor, pencahayaan kurang, mengejar target produksi, aturan setting mesin diabaikan dan tidak ada pelatihan kerja. Faktor penyebab kecacatan dengan RPN tertinggi yaitu operator kurang hati-hati dengan nilai 120.

- Cacat pada sablon, penyebab terjadinya kecacatan yaitu perhatian akan kebersihan kurang, operator kurang hati-hati, stasiun kerja kotor, kurang pengawasan, intensitas penggunaan alat yang tinggi, pencahayaan kurang, mengejar target produksi, aturan setting mesin diabaikan dan tidak ada pelatihan kerja. Faktor penyebab kecacatan dengan RPN tertinggi yaitu operator kurang memperhatikan kebersihan, Intensitas penggunaan alat yang tinggi, operator kurang hati-hati, area kerja kotor, kurang pengawasan dan operator mengabaikan aturang setting dengan nilai 144 .

- Retak/pecah, penyebab terjadinya kecacatan yaitu perhatian akan kebersihan kurang, operator kurang hati-hati, tidak ada kontrol bahan baku, tidak ada gudang penyimpan, stasiun kerja kurang rapi, pencahayaan kurang, mengejar target produksi, aturan setting mesin diabaikan dan tidak ada pelatihan kerja. Faktor penyebab kecacatan dengan RPN tertinggi yaitu operator mengabaikan aturan setting, operator kurang hati-hati, stasiun kerja kurang rapi dengan nilai 240.

3. Usulan rancangan perbaikan kualitas produk labu ukur disesuaikan dengan nilai rpn tertinggi antara lain :

- Operator kurang memperhatikan kebersihan

Mengusulkan agar meningkatkan pengawasan terhadap kebersihan stasiun kerja, memberikan pelatihan dan pengetahuan terhadap pekerja mengenai kualitas produk labu ukur, membuat simbol simbol peringatan mengenai kawasan atau area kerja harus bersih.

- Kehati-hatian kurang operator

Mengawasi pekerja dilakukan secara berkala, memperbaiki SOP tertulis sehingga operator mudah memahami sebelum bekerja dan membuat sistem penilaian kerja.

- Area kerja kotor Mengusulkan agar meningkatkan pengawasan terhadap kebersihan stasiun kerja, memberikan pelatihan dan pengetahuan terhadap pekerja mengenai kualitas produk labu ukur, membuat simbol simbol peringatan mengenai kawasan atau area kerja harus bersih.

- Operator Mengabaikan aturan setting 
Mengusulkan agar dilakukan pengawasan kepada operator secara rutin dan memastikan operator melakukan setting mesin sesuai dengan aturan.

- Intensitas penggunaan alat yang tinggi

Mengusulkan agar memperbaiki alat pada stasiun kerja, mengawasi operator secara berkala pada saat proses produksi dan melakukan perawatan alat atau mesin secara teratur.

- Stasiun kerja kurang rapi

Mengusulkan agar merancang tata letak fasilitas pada stasiun kerja dan melakukan pengawasan kepada para pekerja secara rutin.

\section{Daftar Pustaka}

[1] Assauri, S. (2008). Manajemen Produksi dan Operasi Edisi Revisi. Jakarta: Lembaga Penerbit FE UI.

[2] Purnama, M. (2017, Februari 9). Dipetik Oktober 20, 2018, dari http://karyailmiah.unisba.ac.id/index.php/industri/article/view/6328/pdf

[3] Tannady, H. (2015). Pengendalian Kualitas. Yogyakarta: Graha Ilmu.

[4] Wahyuni, C. H. (2015). Pengendalian Kualitas. Jakarta: Graha Ilmu.

[5] Yumaida. (2011). Analisis Pohon Kesalahan. Analisis Resiko Kegagalan Pemeliharaan, 2021. 